\title{
Government support, social capital and adaptation to urban flooding by residents in the Pearl River Delta Area, China
}

Abstract: Increasingly extreme weather events have resulted in massive socio-economic losses and spark great interest in minimizing the impact of such events in the context of climate change. This paper analyses data from a large-scale household survey conducted in 20 cities in the Pearl River Delta area of China to examine how government support and social capital influence urban residents' adaptations to mitigate the effects of urban flooding. The results show that more than $90 \%$ of residents would take engineering or non-engineering measures to protect their private assets against flooding. The most popular measures are moving away their valuable goods and reducing travel during flooding. Government support, such as releasing early warning information, post-disaster services, technical assistance, financial assistance and physical support could significantly improve residents' adoption of adaptation measures. Social capital, operationalized as having a local Hukou (citizenship) in the area where one works, is closely associated with adaptation capacity, whereas a blood relative network has no evident influence on their adaptation behaviours. In addition, household and local community characteristic have positive influence on residents' adaptations. In summary, government support and community activities are most significant factors influencing residents' adaptation to mitigate the impacts of urban flooding but are in great demand in the Pearl River Delta areas. 
Keywords: adaptation measures; government support; social capital; urban flooding

\section{Introduction}

Urban flooding, has caused considerable damage and loss of life (Reguero et al., 2015; Haddad and Teixeira, 2015). Flooding events occurs at increasing frequency and larger magnitude under the influence of global climate change. There has been considerable interest in how to minimize the impact of floods in advance or amidst the disaster events (Rashid, 2007; IPCC, 2012; Suckall et al., 2014). Given that urban flooding has caused direct asset loss to residents, the household is the basic unit to take adaptation measures against flooding (Blennow and Persson, 2009; Kunreuther, 2006). However, some residents take precautions while others do not (Grothmann and Reusswig, 2006). Many scholars have paid attention to individual factors associated with adaptation to flooding (Witvorapong et al., 2015; Grothmann and Patt, 2005; Bubeck et al., 2012; Huang et al., 2010) and found that personal characteristics, such as age, income, education level, family size, location, real estate ownership and resident's disaster experience, all influence adaptation and mitigation behaviours (Motoyoshi et al., 2004; Blennow et al., 2015; Yu et al., 2013).

Many scholars have found that adaptation actions to water-related events are being undertaken by the government, nongovernment organizations, and private organizations operating at different scales (Witvorapong and Muttarak, 2015; Chen et al., 2014; Pelling, 2005; Adger, 2003; Eakin et al.,2011). Shaw (2012) reported that both government and nongovernment organizations could implement disaster management and risk reduction programs to help residents cope with disasters. 
However, several case studies show that government support and social capital have different effects on the measures taken by residents (Lo et al., 2015; Eriksen and Selboe, 2012; Frank et al., 2011).

In most countries, city governments have drafted and implemented urban adaptation plans to climate change motivated by the need to protect valuable assets and reduce the city's vulnerability (Carter et al., 2015; Milman and Warner, 2016). Though many adaptation measures are similar to planned and top-down approaches, city government is the main actor responsible for preparing for and offsetting damage from climate change hazards. For example, government develops, communicates and implements proactive and responsive adaptation strategies and creates networks between stakeholder groups. City governments also provide material and funding to cope with loss caused by disasters and organize disaster relief activities (Carter et al., 2015). Since the implementation of adaptation activities requires both horizontal coordination among city departments and vertical coordination between government and residents (Hughes, 2015), some scholars have emphasized that the interface between government and private sectors plays an important role in residents' adaptation behaviour (Scolobig et al., 2012). Residents' trust and expectation of government's adaptation will shape their actions in response to floods directly (Chamlee-Wright and Storr, 2009).

Coleman (1990) understands social capital as a largely unintentional outcome of social interactions and organization, and Putnam (1995) defined social capital as an enabler of collective action: "features of social life-networks, norms, and trust that 
enable participants to act together more effectively to pursue shared objectives." Lin (2008) defined social capital as a community- and individual-level attribute related to the resources and information an individual has as a result of his or her social relationships. Pretty and Ward (2001) believe there are four critical aspects of social capital, relations of trust, reciprocity, and exchange; common rules, norms and sanctions; and connectedness, networks, and groups. Many scholars have found that social capital among members of a community is a key determinant of the community's vulnerability and resilience to environmental changes and uncertainties. For example, Adger (2003) believed that the structure and quality of social relations select which impending change to act upon and determine the type and range of options for coping with (environmental) changes. The relationships between persons within the community will shape individual's perception of climate change and related disasters. Frank et al. (2011) found that people's relation with their community will influence their understanding and response to climate-related threats, and Goulden et al. (2013) found that social capital could give people more opportunity to mitigate and spread the risk of environmental change. However, some scholars believe that the accumulation of social capitals is not necessarily a social good and may create perverse incentives, undermining adaptive capacity. They found norms and trust may perpetuate social relations that will delay or be counter-productive to adaptation to condition changes (Wolf et al., 2010). Thus, the structure of social relations and practice has a mixture of impacts on individual adoption measures, and the relationship between social capital and adaptation to climate change is complex 
and not invariably a positive one (Pelling, 2011; Lo et al., 2015).

The Pearl River Delta (PRD) area in South China has long been recognized as highly sensitive to sea level rise and extreme weather events, such as storm surges and hurricanes. The area's special geographic location and physical environment make it vulnerable to urban flooding caused by heavy rainfall, storm tides and sea level rise accompanied by low human adaptive capacity and high exposure (CMA, CAS, \& MOST, 2011; Chan et al., 2012; Yang et al., 2015; Wang et al., 2014; Fuchs et al., 2011; Du et al., 2015). In addition, as one of the most rapidly urbanizing areas in China (China Daily, 2012), large areas of land of the PRD are covered by buildings and cement that are resistance to rainwater absorption, thereby increasing surface runoff and rainwater accumulation contributing to urban flooding (Yang et al., 2015). The rapid urbanization of the PRD area has also resulted in a large floating population settlement in newly built-up areas, leading to social fragmentation, instability in social capital and lack of community cohesion (Liu et al., 2010; Wang et al., 2009). This means that it is more difficult to understand the factors influencing the efforts at disaster preparation and mitigation in the PRD than in other regions.

In China, government-dominated urban management can be assumed to be primarily responsible for managing flood risks. In most situations, the government is responsible for investing and sustaining public hydraulic engineering projects, such as reservoirs, water-gates and embankments. Beyond disaster engineering prevention and reduction projects, the government has also stressed the role of non-engineering projects in disaster prevention and reduction, such as information collection systems 
and flooding forecast and controlling systems (He et al., 2010). It is, therefore, vital to examine how residents have adapted to the risk of urban floods and consider how the government provides support and social capital influence on adaptation. What anti-flood measures did residents take in the PRD area? Did the government's support and social capital facilitate resident's adaptation efficiently? This research will help improve our understanding of how government and community activity influence individual behaviour and hence help the government improve disaster prevention and mitigation measures.

This study is organized as follow. Firstly, we outline the design of the survey and the sources of data. Then, we describe the protective measures residents have taken to cope with floods. Thirdly, we analyse how government support and social capital influence protective behaviour using qualitative and quantitative techniques. Finally, we discuss the policy implications of our findings and provide proposals for improving residents' capacity to mitigate flood.

\section{Study area and methodology}

The PRD is located in the south-central part of the Guangdong Province in Southern China (Fig 1). Guangdong is one of the most vulnerable provinces to urban flooding caused by heavy rain and storm surges in China. Over the past half century, Guangdong has witnessed multiple storm surges annually. Each storm surge caused serious urban flooding and economic loss (Chen, 1999; Yang et al., 2013).

The data were obtained from a large-scale survey conducted in 20 cities of the PRD between July 5th and July 15th of 2013. In the survey, four locations that had 
suffered from flooding in the past three years were chosen in each city according to previous home investigation and research. Most of the locations are in the old city and fringe areas and are vulnerable to water-logging due to fast rain water accumulation combined with poor local drainage. At least 15 households in each location were interviewed. As a result, we obtained a total of 1209 complete questionnaires.

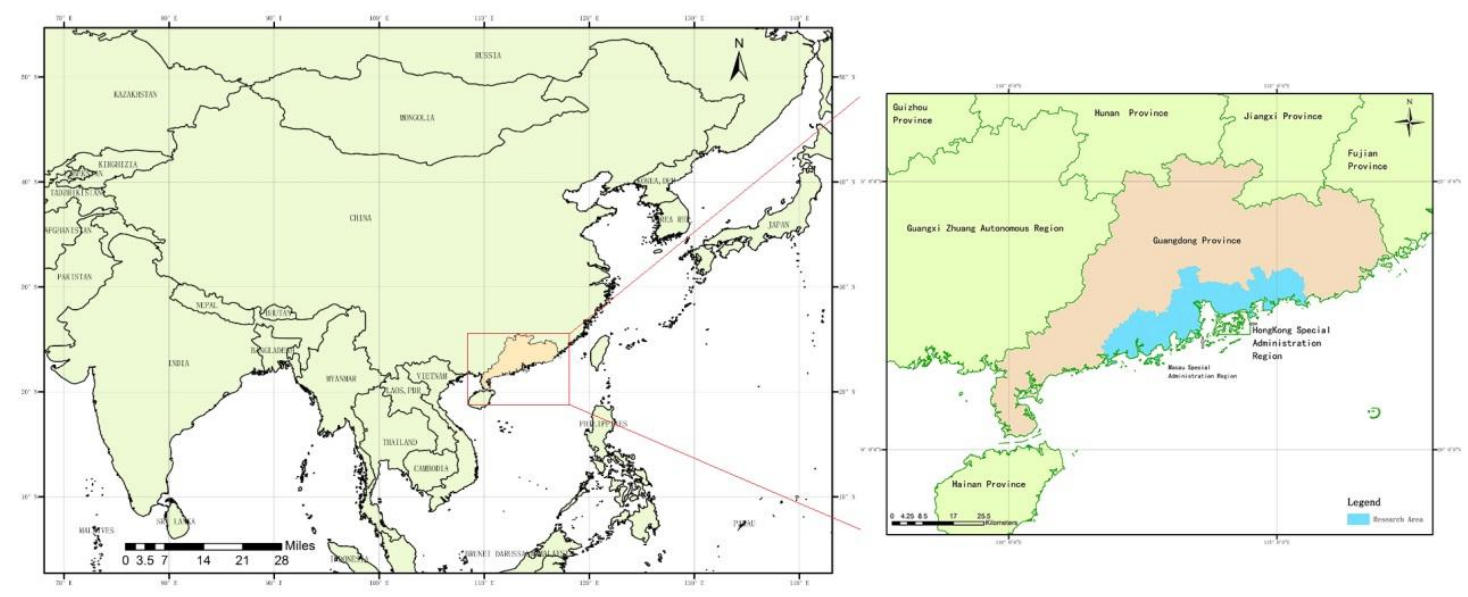

Fig. 1 Study area

The aim of the survey was to investigate the influence of climate change on individual life and how residents have adapted to and coped with it. We collected data on demographic characteristics, location, economic status, social networks, damage caused by urban flooding, prevention and mitigation measures, and material or financial support to implement anti-flood measures from all respondents. The basic characteristics of respondents are shown in Table 1. Most respondents were between 18 and 55 years old, the modal educational level was middle school, and most respondents lived in rented accommodations in the old district and the rural-urban fringe area.

Table 1. Respondent characteristics: descriptive statistics 


\begin{tabular}{|c|c|c|c|}
\hline Variable & Category & $\begin{array}{l}\text { Number of } \\
\text { respondents }\end{array}$ & $\begin{array}{l}\text { Percentage of } \\
\text { respondents }\end{array}$ \\
\hline \multirow{6}{*}{ Respondent age in years } & under 18 & 20 & 1.7 \\
\hline & $18-30$ & 269 & 22.2 \\
\hline & $31-45$ & 479 & 39.6 \\
\hline & $46-55$ & 229 & 18.9 \\
\hline & $56-65$ & 138 & 11.4 \\
\hline & over 65 & 74 & 6.1 \\
\hline \multirow{5}{*}{ Education level } & Primary school or below & 280 & 23.2 \\
\hline & Junior middle school & 477 & 39.5 \\
\hline & Senior middle school & 321 & 26.6 \\
\hline & $\begin{array}{l}\text { University or college } \\
\text { degree }\end{array}$ & 123 & 10.2 \\
\hline & Post-graduate qualification & 8 & 0.7 \\
\hline \multirow{3}{*}{ Household location } & Old district & 728 & 60.2 \\
\hline & Urban village & 92 & 7.6 \\
\hline & Urban fringe & 389 & 32.2 \\
\hline \multirow{2}{*}{ Ownership status } & Owner & 514 & 42.5 \\
\hline & Non-owner & 695 & 57.5 \\
\hline \multirow{2}{*}{$\begin{array}{l}\text { Loss of assets due to } \\
\text { flooding }\end{array}$} & Yes & 985 & 81.5 \\
\hline & No & 224 & 18.5 \\
\hline
\end{tabular}

\section{Anti-flood measures taken by residents}

We use the term adaptation to refer to engineering or non-engineering adaptations

(Chen et al., 2014), a definition that is widely accepted by residents and local government. We also distinguish between simple and complex adaptation measures according to implementation complexity and cost. Complex engineering measures mean that the project involves a considerable investment, more than 1000 RMB Yuan, or that complicated maintenance work could not be finished by one household only, such as strengthening buildings, repairing dams, clearing public drains, and building high-quality waterproof steps in front of doors. Simple engineering measures involve costs of less than 1000 RMB Yuan or simple works that could be finished by one household, such as moving fragile and valuable property to safer places to avoid being 
flooded and putting sandbags in front of doors. Complex non-engineering measures are mostly related to finances, such as purchasing insurance and increasing savings. The term simple non-engineering measures is used to refer to lifestyle measures, such as reducing travelling, changing one's working schedule and mode and moving away from flood risk zones. We asked the residents to recall what types of adaptation measures they had adopted previously, during and after the most serious flooding event of the past three years.

The results show that $91.7 \%$ of the residents of the 1209 surveyed households took some measures to protect their properties against inundation (Table 2). The proportion of residents taking non-engineering measures $(84.9 \%)$ was slightly higher than the proportion taking engineering measures (79.4\%). Most residents who took non-engineering measures adopted simple non-engineering measures. As Table 2 shows, $74.6 \%$ of residents took only simple non-engineering measures and only $0.3 \%$ of residents took only complex non-engineering measures. Only $10.0 \%$ of residents in this sample adopted both types of non-engineering measures. There was a similar pattern to the adoption of engineering measures: $40.8 \%$ of residents took only simple engineering measures and $12.4 \%$ took only complex engineering measures; $26.2 \%$ of residents took both types of engineering measures.

Table 2. Measures taken against urban flooding

\begin{tabular}{lcc}
\hline & Number of households & Percentage of households \\
\hline Whole sample & 1209 & 100 \\
None & 100 & 8.3 \\
Non-engineering measures & 1027 & 84.9 \\
$\quad$ Only simple measures & 902 & 74.6 \\
\hline
\end{tabular}




\begin{tabular}{ccc}
\hline Only complex measures & 4 & 0.3 \\
Both types & 121 & 10.0 \\
Engineering measures & 960 & 79.4 \\
Only simple measures & 493 & 40.8 \\
Only complex measures & 150 & 12.4 \\
Both types & 317 & 26.2 \\
\hline
\end{tabular}

Further analyses show that the engineering measures taken included both moving personal property and reducing the vulnerability of one's house. Some residents used more than one engineering measure to cope with inundation. The field survey indicated that $77.7 \%$ of residents moved fragile or valuable property to safe locations; $19.4 \%$ of households reinforced outdoor properties, such as air conditioning; and $22.6 \%$ of households took other simple engineering measures, such as barricading properties and pumping (Fig 2). Turning to complex engineering measures, $27.0 \%$ of households built a pedestal at the door of the house, $18.5 \%$ cleared drains, and $10.5 \%$ strengthened their house. Other complex engineering options were used by $2 \%$ or fewer households, for example, repairing dams (2.0\%).

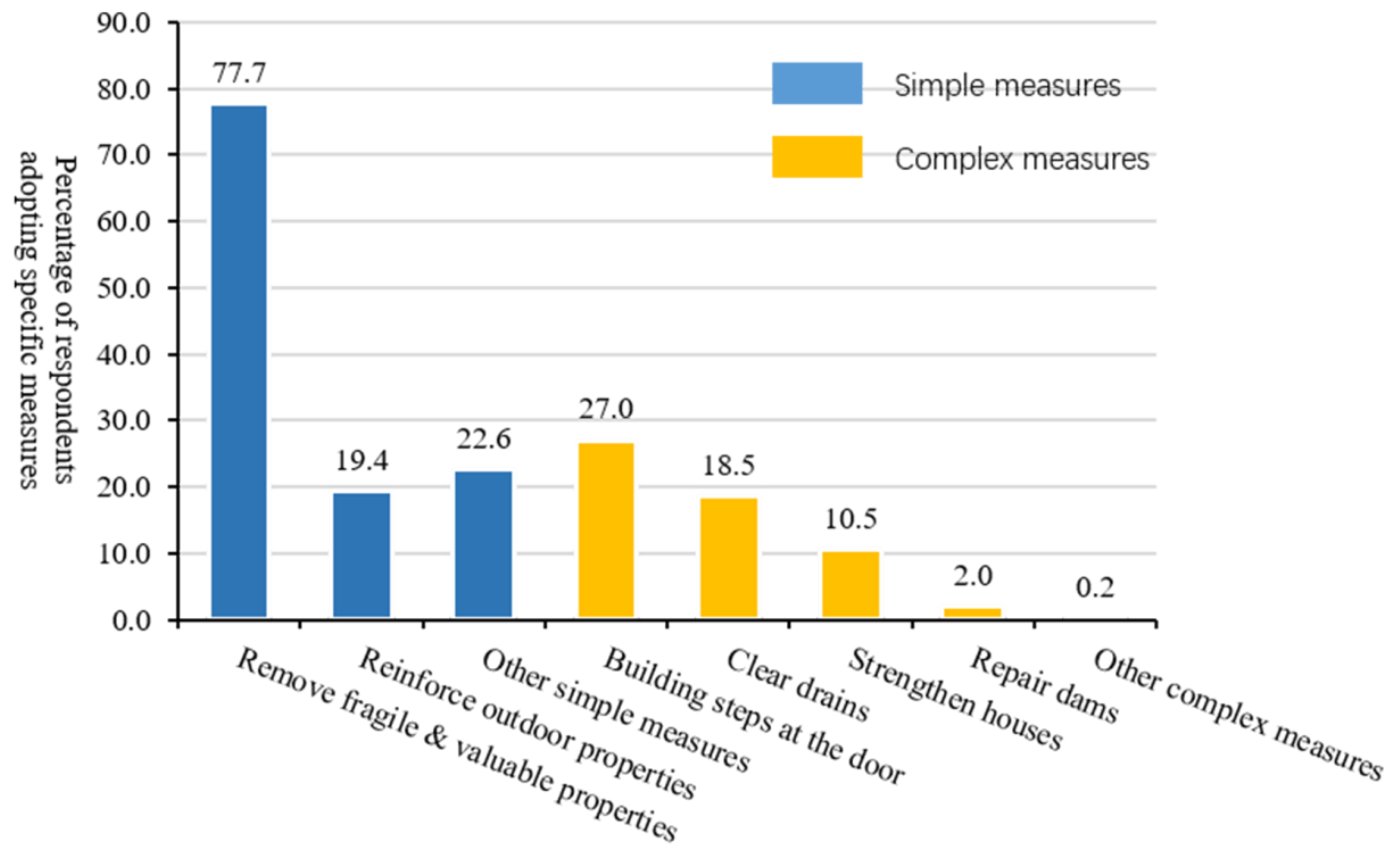

Engineering adaptation measures

Fig 2. Engineering measures adopted by residents in the Pearl River Delta 
The two most commonly used non-engineering measures are changing behavioural routines and moving away from flood risk zones. Of the households that took non-engineering measures, $90.3 \%$ preferred to stay indoors and reduce traveling outdoors, $44.8 \%$ changed their working schedule and mode of work, and $40.2 \%$ moved away from the danger areas (Fig 3). These non-engineering measures are easier and less costly to adopt than some financial non-engineering measures. Only $10.3 \%$ of households took complex non-engineering measures to increase their financial capital, such as buying insurance (6.3\%), increasing savings (3.7\%) or reducing spending $(3.6 \%)$.

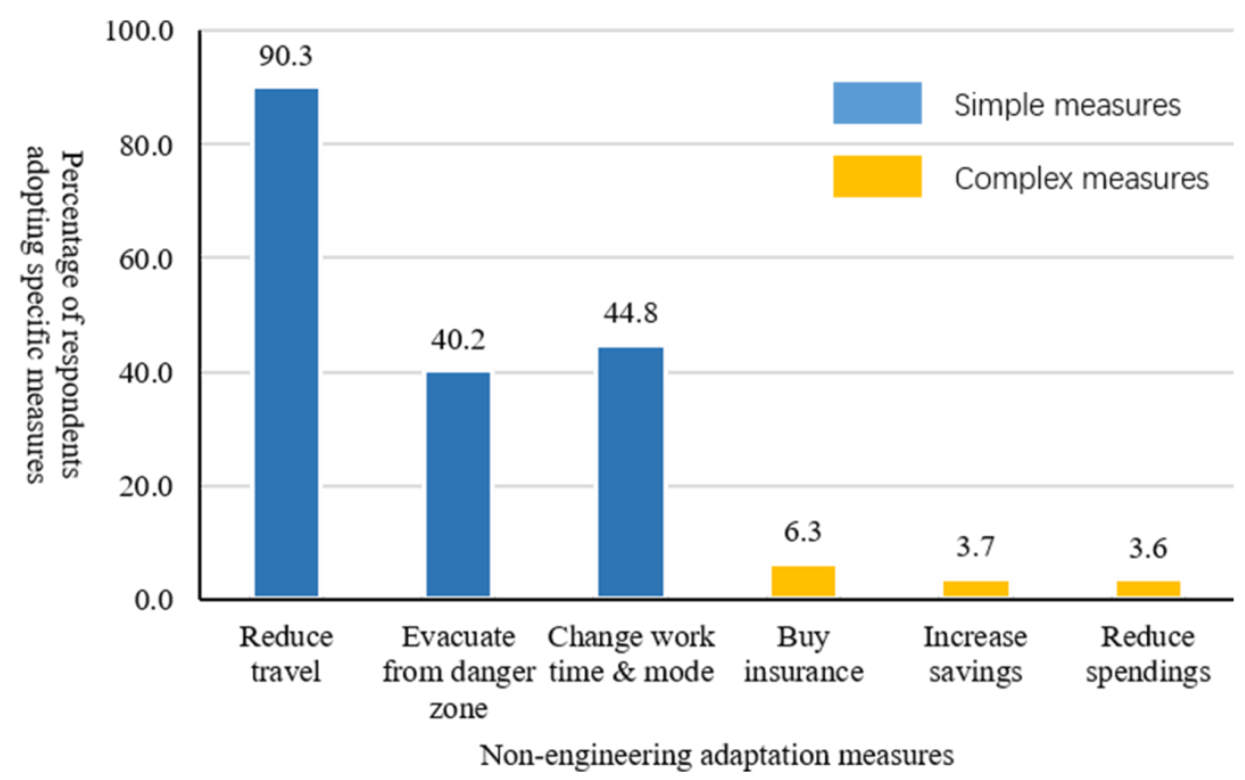

Fig 3. Non-engineering measures adopted by residents in Pearl River Delta

\section{Government support, social capital and adaptation by residents}

\subsection{Government support}

Apart from the general adaptation plan, government's concrete and direct support for residents threatened by flooding can be divided into three categories. First, 
provision of early warnings of flooding and advice on mitigation; second, provision of financial, material and human support during and after a flood event; and third, provision of technical support, such emergency response training to increase residents' capacity to cope effectively with flood events. Early dissemination of warning and prevention information can be achieved in many ways, such as sending messages to residents' mobile phones; broadcasting information through radio, television, the Internet and meetings; and even by issuing authority documents to related departments and communities. Early warning and mitigation information mainly consists of information about the likely timing, duration, and severity of flooding and suggesting coping responses. Some local governments offer technical support in the form of drills or training to help residents cope better with flooding.

The survey shows that there are wide variations in residents' cognition of real government support access. For example, $85.9 \%$ of households received warnings and prevention information before the flood (Table 3), but only $8.5 \%$ received technical support and only 9.0\% received direct material support from local government (Table 4).

Table 3. Provision of government support

\begin{tabular}{lcc}
\hline & Number of respondents & Share of respondents $(\%)$ \\
\hline All respondents & 1209 & 100 \\
Information support not received & 171 & 14.1 \\
Information support received & 1038 & 85.9 \\
Technical support not received & 1106 & 91.5 \\
Technical support received & 103 & 8.5 \\
Direct material support not received & 1100 & 91.0 \\
Direct material support received & 109 & 9.0 \\
\hline
\end{tabular}


Table 4. Proportion of household taking non-engineering anti-flood measures provided by government support

\begin{tabular}{|c|c|c|c|c|}
\hline & $\begin{array}{l}\text { Overall percentage } \\
\text { of respondents } \\
\text { who took } \\
\text { non-engineering } \\
\text { measure (\%) }\end{array}$ & $\begin{array}{c}\text { Percentage taking } \\
\text { only simple } \\
\text { measures }(\%)\end{array}$ & $\begin{array}{l}\text { Percentage taking } \\
\text { only complex } \\
\text { measures }(\%)\end{array}$ & $\begin{array}{c}\text { Percentage taking } \\
\text { both types of } \\
\text { measure (\%) }\end{array}$ \\
\hline $\begin{array}{l}\text { Information support not } \\
\text { received }\end{array}$ & 77.2 & 72.5 & 0.0 & 4.7 \\
\hline $\begin{array}{l}\text { Information support } \\
\text { received }^{1}\end{array}$ & $86.2 * * *$ & 75.0 & 0.4 & $10.9 * * *$ \\
\hline $\begin{array}{l}\text { Technical support not } \\
\text { received }\end{array}$ & 84.4 & 74.7 & 0.3 & 9.4 \\
\hline $\begin{array}{l}\text { Technical support } \\
\text { received }^{1}\end{array}$ & $91.3^{* * *}$ & 73.8 & $1.0 * *$ & $16.5 * * *$ \\
\hline $\begin{array}{l}\text { Direct material support } \\
\text { not received }\end{array}$ & 84.6 & 75.3 & 0.4 & 9.0 \\
\hline $\begin{array}{l}\text { Direct material support } \\
\text { received }^{1}\end{array}$ & $88.1^{* * *}$ & $67.9 * * *$ & 0.0 & $20.2 * * *$ \\
\hline
\end{tabular}

Notes.

* shows the degree of significance obtained by the non-parametric T-test to examine whether there is a significant difference between two groups of data. In this table, we used 12 groups for the T-test. The $*$ denotes a significant difference between the interest group and control group. That is, the proportion of families taking certain measures is significantly more than / less than the proportion of households that do not take such measures.

$*$ shows significance at the $10 \%$ level; $* *$ shows significance at the $5 \%$ level; $* * *$ shows significance at the $1 \%$ level.

Does government support facilitate residential adoption of non-engineering adaptation measures against urban flooding? As shown in Table 4, 86.2\% of households that received early warning and mitigation information adopted some non-engineering coping measures, a much higher proportion than those who did not receive any information. Provision of information seemed to increase the probability 
of both types of non-engineering measures being adopted. Where the local government offered technical support, such as drills or training, $91.3 \%$ of households adopted some non-engineering measure; where the government did not provide this support, the proportion of households taking non-engineering measures dropped to $84.4 \%$. Households were significantly more likely to take complex non-engineering measures or both types of non-engineering measure if government-initiated technical support was provided. Provision of direct material support also increased the proportion of households adopting non-engineering adaptation measures, from $84.6 \%$ to $88.1 \%$.

Table 5. Proportion of households taking engineering anti-flood measures given the provision of government support

\begin{tabular}{|c|c|c|c|c|}
\hline & $\begin{array}{l}\text { Overall percentage } \\
\text { of respondents } \\
\text { who took } \\
\text { engineering } \\
\text { measure }(\%)\end{array}$ & $\begin{array}{c}\text { Percentage taking } \\
\text { only simple } \\
\text { measures }(\%)\end{array}$ & $\begin{array}{c}\text { Percentage taking } \\
\text { only complex } \\
\text { measures (\%) }\end{array}$ & $\begin{array}{c}\text { Percentage taking } \\
\text { both types of } \\
\text { measure }(\%)\end{array}$ \\
\hline $\begin{array}{l}\text { Information support not } \\
\text { received }\end{array}$ & 69.0 & 37.4 & 9.9 & 21.6 \\
\hline $\begin{array}{l}\text { Information } \quad \text { support } \\
\text { received }^{1}\end{array}$ & $81.1 * * *$ & $41.3^{* *}$ & $12.8^{* *}$ & $27.0 * * *$ \\
\hline $\begin{array}{l}\text { Technical support not } \\
\text { received }\end{array}$ & 78.4 & 40.7 & 12.1 & 25.6 \\
\hline $\begin{array}{l}\text { Technical } \\
\text { received }^{1}\end{array}$ & $90.3 * * *$ & 41.7 & 15.5 & $33.0 * * *$ \\
\hline $\begin{array}{l}\text { Direct material support } \\
\text { not received }\end{array}$ & 79.0 & 41.7 & 12.3 & 25.0 \\
\hline $\begin{array}{l}\text { Direct material support } \\
\text { received }^{1}\end{array}$ & $83.5^{* *}$ & $31.2 * * *$ & 13.8 & $38.5 * * *$ \\
\hline
\end{tabular}

Notes. 
${ }^{1}$ Compared with the row above using a t-test.

* Significant at the $10 \%$ level; ** significant at the $5 \%$ level; *** significant at the $1 \%$ level.

Does government support encourage residents to take engineering measures against flooding? As shown in Table 5, when early warning and mitigation information was provided, $81.1 \%$ of households took engineering measures, compared to only $69.0 \%$ of households that did not receive such information. Specifically, this relationship held true for the adoption of any engineering measures, such as only simple, only complex, and both types of engineering measures. While $90.3 \%$ of households that received technical support from the government adopted engineering measures, this was true of only $78.4 \%$ of households that did not. Similarly, the government provided direct material support to $83.5 \%$ of households that took engineering measures, compared to $79.0 \%$ of households that did not receive direct material support from the government.

\subsection{Social capital and residents' adaptation to flooding}

The important role of social capital in adapting to disasters has been widely recognized in recent years. Social capital can not only help residents acquire necessary information and simplify loan applications but also promote the adoption of new technologies by internalizing the externality of these technologies through the social network. In this study, we take the number of relatives of a household within three generations living in the immediate county, the number of phone contacts and the combination of Hukou (Chinese resident's citizenship system) and job location as indicators of social capital. If a resident has a large number of blood relatives and 
phone contacts, this resident has a large amount of social capitals. The combination of Hukou and job location could be described in terms of four distinct categories: local Hukou and local job (LL); local Hukou and non-local job (LN); non-local Hukou and local job (NL); non-local Hukou and non-local job (NN). Since the local Hukou category means the resident has been accepted by the local society and has relatively better social security, stable possessions, and social network, we assumed that people in the LL category would have higher social capitals than those in the NN category.

Does social capital embodied in the Hukou-job location relationship have a significant impact on the adoption of both engineering and non-engineering measures? We found that LL residents were more likely than NN residents to have adopted non-engineering measures ( $86.6 \%$ and $64.7 \%$, respectively); $77.6 \%$ and $84.7 \%$ of members of groups LN and NL took non-engineering measures, still significantly less than those in group LL (Table 6). Specifically, residents in the LL group were more likely to have adopted only simple non-engineering measures than those in the LN and NN groups. A similar pattern applied to engineering measures, and the proportion of residents adopting such measures was highest for the LL group (81.5\%), lowest for the NN group (64.7\%) and higher for the NL group (78.2\%) than the LN group (71.4\%). The same pattern applied to the adoption of both types of engineering measures. There was a different pattern, however, for the adoption of only complex engineering measures. Residents in the NL group were most likely to adopt only complex engineering measures and residents in the LN group were least likely to do so. 
Table 6. Proportion of households taking anti-flood measures given different indicators of social capital

\begin{tabular}{lcccc}
\hline & \multicolumn{4}{c}{ Hukou-job location category } \\
& $\begin{array}{c}\text { local-local } \\
\text { (LL) }\end{array}$ & $\begin{array}{c}\text { local-non-local } \\
(\mathrm{LN})^{1}\end{array}$ & $\begin{array}{c}\text { non-local-local } \\
(\mathrm{NL})^{1}\end{array}$ & $\begin{array}{c}\text { non-local-non-local } \\
(\mathrm{NN})^{1}\end{array}$ \\
\hline $\begin{array}{l}\text { Respondents taking } \\
\text { non-engineering measures }\end{array}$ & 86.6 & $77.6^{* * *}$ & $84.7^{*}$ & $64.7^{* * *}$ \\
Only simple measures & 76.4 & $63.3^{* * *}$ & 74.8 & $52.9^{* * *}$ \\
Only complex measures & 0.3 & 0.0 & 0.4 & 0.0 \\
Both types of measure & 10.0 & $14.3^{*}$ & 9.4 & 11.8 \\
& & & & \\
Respondents taking engineering & 81.5 & $71.4^{* * *}$ & $78.2^{* * *}$ & $64.7^{* * *}$ \\
measures & 41.4 & 46.9 & $38.9 *$ & 44.1 \\
Only simple measures & 11.5 & $2.0^{* * *}$ & $15.3^{* * *}$ & 8.8 \\
Only complex measures & 28.6 & $22.4^{* *}$ & $24.0^{* * *}$ & $11.8^{* * * *}$ \\
Both types of measure & & &
\end{tabular}

Notes:

${ }^{1}$ Compared with LL using a t-test.

* Significant at the $10 \%$ level; ** significant at the 5\% level; *** significant at the $1 \%$ level.

Do the larger number of blood relatives and phone contacts facilitate residents to take adaptation measures? For convenience, we classified the number of blood relatives into four categories, category 1: less than 5; category 2: 5 to 10 ; category 3 : 11 to 20; and category 4: more than 20 . The number of phone contacts was similarly categorized, category 1: less than 20; category 2: 21 to 50; category 3: 51 to 100 ; and category 4: more than 100. Table 7 shows that this type of social capital was negatively associated with adoption of coping measures. The average blood relative category for residents adopting non-engineering measures was lower than that for residents not adopting such measures, and the average values for residents adopting both and only complex non-engineering measures are both much smaller, reflecting a 
negative association between the number of blood relatives living in the same locality and the likelihood of adopting non-engineering measures. The same pattern of associations was seen in relation to engineering measures. The number of phone contacts was also associated with adoption of non-engineering measures. The average phone contact category for residents who took non-engineering measures was 2.4, which is significantly lower than that of residents who did not adopt such measures (2.5). A similar pattern applied to adoption of only simple non-engineering measures and both types of non-engineering measures.

Table 7. Average scores of different category for adoption of anti-flood measures

\begin{tabular}{lcc}
\hline & \multicolumn{2}{c}{ Average category } \\
& $\begin{array}{c}\text { Relatives within three } \\
\text { generations in the same } \\
\text { locality }\end{array}$ & $\begin{array}{c}\text { Number of phone } \\
\text { contact }\end{array}$ \\
\hline${\text { Respondents not taking non-engineering measures }{ }^{1}}^{1}$ & 2.8 & 2.5 \\
Respondents with non-engineering measures $^{1}$ & 2.7 & $2.4^{* * *}$ \\
Only simple measures $^{1}$ & 2.8 & $2.4^{* *}$ \\
Only complex measures $^{1}$ & $2.3^{*}$ & 1.5 \\
Both types of measure $^{1}$ & 2.6 & $2.2^{* * *}$ \\
& & \\
Respondents not taking engineering measures $^{2}$ & 2.8 & 2.4 \\
Respondents taking engineering measures $^{2}$ & 2.7 & 2.4 \\
Only simple measures $^{2}$ & 2.8 & 2.5 \\
Only complex measures $^{2}$ & 2.8 & 2.3 \\
Both types of measure $^{2}$ & 2.7 & 2.4 \\
\hline
\end{tabular}

Notes:

${ }^{1}$ Compared with row ${ }^{1}$ using a t-test; ${ }^{2}$ compared with row ${ }^{2}$ using a t-test.

* Significant at the $10 \%$ level; ** significant at the $5 \%$ level; *** significant at the $1 \%$ level. 


\section{Econometric model and estimation results}

\subsection{Specification and estimation of econometric models}

Adoption of measures to cope with flooding may also be influenced by other factors, such as personal characteristics, household location, experience of coping with floods and ownership status. To quantify the influence of government support and social capital quantitatively, an econometric model was specified, as follows, suggested by Chen et al. (2014):

$$
\begin{gathered}
Y_{N E}=\alpha+\beta \mathrm{G}+\gamma \mathrm{S}+\delta \mathrm{P}+\lambda \mathrm{L}+\mu \mathrm{E}+\omega \mathrm{O}+\varepsilon \\
Y_{E}=\alpha+\beta \mathrm{G}+\gamma \mathrm{S}+\delta \mathrm{P}+\lambda \mathrm{L}+\mu \mathrm{E}+\omega \mathrm{O}+\varepsilon
\end{gathered}
$$

In model (1) the dependent variable $Y_{N E}$ represents the type of non-engineering measure; in model (2) $Y_{E}$ represents the type of engineering measure. Both variables are coded $0,1,2$ or 3 . If a household did not take any adaptation measures, $\mathrm{Y}$ is set to 0 ; if a household took only simple adaptation measures, $\mathrm{Y}$ is set to 1 ; if a household took only complex adaptation measures, $\mathrm{Y}$ is set to 2 ; and if a household did both types of adaptation measures, $\mathrm{Y}$ is set to 3 .

The independent variables are defined as follows. G represents government support received by a household and is one of the variables of special interest. G is a vector variable, representing the following information: (a) receipt of early warning and mitigation information (coded as a binary dummy variable: $1=$ information received; 0 = information not received); (b) receipt of government technical support $(1=$ support received; $0=$ no support $) ;$ and (c) receipt of direct material support from government $(1=$ support received; $0=$ no support $)$. 
$S$ represents social capital. The first type of $G$ is operationalized as the combination of Hukou (citizenship) and job location, which is described as a nominal variable with 4 categories: local Hukou and local job (LL), local Hukou and non-local job (LN), non-local Hukou and local job (NL), non-local Hukou and non-local job $(\mathrm{NN})$. The second type of $\mathrm{G}$ is a vector variable containing the following information: (a) number of relatives within three generations living in the immediate locality (for convenience this number was classified into four categories, category 1: less than 5; category 2: 5 to 10; category 3: 11 to 20; category 4: more than 20); (b) number of phone contacts a resident has (four categories, category 1: less than 20; category 2: 21 to 50 ; category 3 : 51 to 100 ; category 4 : more than 100 ) on the other side.

P represents a resident's personal characteristics and comprises the following: (1) education level, measured as an ordinal variable ranging from 1 to $5(1=$ did not attend school or only finished primary school; 2 = finished junior middle school; $3=$ finished senior middle school or equivalent; 4 = graduated from university of a junior college; 5 = achieved a post-graduate qualification); (2) age, measured as an ordinal variable ranging from 1 to 6 (boundary values are 18, 30, 45, 55 and 65 years, respectively).

L represents the household location as a categorical variable with three values (1 = old district; 2 = urban village; 3 = urban fringe). E represents the flooding experience $(1=$ yes; $0=$ no). $\mathrm{O}$ is used to indicate whether the resident owned his or her home $(1=$ owner; 0 = non-owner $)$.

In the model, $\alpha, \beta, \gamma, \delta, \lambda, \mu$ and $\omega$ are parameters to be estimated and $\varepsilon$ is a 
random term. Given that the dependent variable is a categorical variable, we used the multinomial logit model to estimate models (1) and (2). In these models, the dependent variables are converted to the logged odds of the outcomes as a linear combination of the predictor variables. Thus, the value of parameters means the change quantity of the logged odds of the interest category rather than the reference category when the corresponding independent variable changes one-unit. When the signs of the parameters are positive, it indicates that the corresponding independent variable increases the likelihood of the dependent variable. For the sake of simplicity, we only refer to the sign of the parameters to analyse the direction of the relationship.

\subsection{Estimation results}

As shown in Table 8, the models perform well; the likelihood-ratio statistics for both models are significant at the $1 \%$ level and passes the Chi-squared test. The sign of the control variables reveals that the estimation results are plausible. For example, the signs of effects of ownership of houses are statistically significant and in positive directions for use of only simple non-engineering measures, both types of non-engineering measures and engineering measures. This implies that the residents of home owners are more likely to adopt non-engineering and engineering measures than tenants. The model results also indicate that residents who had been flooded before are more likely to take some engineering measure and simple non-engineering adaptation measures.

The interesting results are those related to education level and age. Resident age has no effect on adoption of any measure, whereas education level has a non-linear 
influence on adoption of engineering measures. Residents who had completed senior middle school or held a first degree (codes 3 and 4) are less likely to adopt only simple engineering adaptation measures or complex engineering adaptation measures than residents who had only completed primary school (code 1). This may be because more educated residents tend to have a better living environment that is less vulnerable to inundation; however, this does not explain why there is no difference between residents with a post-graduate qualification (code 5) and residents who had only completed primary education (code 1) with respect to these measures. Further fieldwork is needed to explain this pattern of results.

Household location also has an impact on the adoption of anti-flood measures. As shown in Table 9, after controlling for the influence of other confounding factors, residents in urban villages are more likely to adopt only simple non-engineering measures and less likely to adopt only simple engineering measures in comparison to residents living on the urban fringe. There is no difference between residents of the urban fringe and the old district on adoption of anti-flood measures.

Table 8. Estimation results on the determinants of residential adoption of anti-flood measures.

\begin{tabular}{|c|c|c|c|c|c|c|}
\hline & \multicolumn{3}{|c|}{$\begin{array}{l}\text { Non-engineering measures } \\
\text { (Control group: those not } \\
\text { adopting non-engineering } \\
\text { measures) }\end{array}$} & \multicolumn{3}{|c|}{$\begin{array}{l}\text { Engineering measures (Control } \\
\text { group: those not adopting } \\
\text { engineering measures) }\end{array}$} \\
\hline & $\begin{array}{c}\text { Only } \\
\text { simple }\end{array}$ & $\begin{array}{c}\text { Only } \\
\text { complex }\end{array}$ & $\begin{array}{l}\text { Both } \\
\text { types }\end{array}$ & $\begin{array}{c}\text { Only } \\
\text { simple }\end{array}$ & $\begin{array}{c}\text { Only } \\
\text { complex }\end{array}$ & $\begin{array}{l}\text { Both } \\
\text { types }\end{array}$ \\
\hline \multicolumn{7}{|c|}{ Hukou-job location (control group: NN) } \\
\hline LL & $1.06^{* *}$ & 14.98 & 0.53 & 0.48 & 0.73 & $1.15^{*}$ \\
\hline $\mathrm{LN}$ & 0.31 & 0.43 & 0.15 & 0.30 & -1.19 & 0.62 \\
\hline NL & $1.09 * *$ & 14.91 & 0.86 & 0.20 & 0.89 & 0.98 \\
\hline
\end{tabular}


generations living in the same locality

(control group: less than 5)

$$
\begin{aligned}
& 5 \text { to } 10 \\
& 10 \text { to } 20
\end{aligned}
$$

more than 20

Number of phone contacts (control group:

less than 20)

$$
\text { 20-50 }
$$

50-100

more than 100

Technical support from government

(1=yes; $0=$ no)

Information support from government

(1=yes; $0=$ no)

Direct material support from government (1=yes, $0=$ no)

Respondent age in years (control group: under 18)

$$
\begin{aligned}
& 18-30 \\
& 31-45 \\
& 46-55 \\
& 56-65 \\
& \text { over } 65
\end{aligned}
$$

Education level (control group: primary school or below)

Junior middle school
Senior middle school
University or college degree
Postgraduate qualification

Community type (control group: urban fringe)

Old district
Urban village

Ownership status (1=owner;

$0=$ non-owner)

Experience of being flooded ( $1=$ yes, $0=$ no) Intercept

$$
\begin{aligned}
& \text { LR chi }^{2} \\
& \text { Nagelkerke's R }{ }^{2}
\end{aligned}
$$

$\begin{array}{cccccc}0.60^{* * *} & 14.86 & 1.25^{* * *} & 0.08 & 0.21 & 0.76^{* * * *} \\ -0.08 & 15.54 & 0.61 & -0.16 & -0.31 & 0.29 \\ 0.29 & -0.29 & 1.35^{* * *} & 0.12 & 0.55 & 0.65\end{array}$

$\begin{array}{cccccc}-0.21 & 13.85 & -0.94 * * & 0.12 & 0.15 & 0.09 \\ -0.42 & -1.76 & -1.34 * * * & -0.04 & 0.54 & -0.38 \\ 0.24 & 15.09 & 0.09 & 0.28 & 0.65 * & 0.21 \\ 0.49 & 1.03 & 0.61 & 1.08 * * * & 1.11 * * & 1.17 * * *\end{array}$

$\begin{array}{llllll}0.60 * * * & 14.15 & 1.13 * * * & 0.77 * * * & 0.83 * * * & 0.80 * * *\end{array}$ $\begin{array}{llllll}-0.02 & -14.32 & 0.83^{* *} & -0.16 & 0.16 & 0.55^{*}\end{array}$

$\begin{array}{llllll}-0.17 & 14.19 & -0.79 & -0.60 & -0.42 & -0.37 \\ -0.10 & 13.63 & -0.59 & -0.40 & -0.10 & -0.18 \\ -0.36 & -1.15 & -1.30 & -0.67 & 0.02 & -0.55 \\ 0.09 & -1.07 & -0.75 & -0.64 & 0.37 & -0.40 \\ -0.48 & 1.24 & -1.25 & -0.70 & -0.35 & -0.45\end{array}$

$\begin{array}{cccccc}-0.01 & 14.34 & 0.31 & -0.27 & -0.23 & 0.13 \\ 0.05 & 13.87 & 0.22 & -0.67 * * & -0.89 * * * & -0.10 \\ -0.48 & -1.69 & 0.53 & -0.81 * * & -0.87 * & -0.26 \\ -1.30 & -3.35 & -1.18 & -20.79 & -21.11 & -1.96\end{array}$

\begin{tabular}{cccccc}
-0.30 & -0.69 & -0.21 & 0.02 & -0.30 & 0.02 \\
$0.85^{*}$ & -13.38 & 0.92 & $-0.57 *$ & -0.22 & -0.50 \\
$0.73 * * *$ & 0.08 & $0.97 * * *$ & 0.22 & 0.19 & $0.49 * *$ \\
$0.79 * * *$ & 0.31 & -0.09 & $1.11 * * *$ & $0.53 * *$ & $1.89 * * *$ \\
-0.54 & -88.42 & $-2.13 *$ & -0.41 & $-2.15^{*}$ & $-3.37 * * *$ \\
& $179.747 * * *$ & & & $214.785^{* * *}$ \\
& 0.178 & & & 0.176 \\
\hline
\end{tabular}

Notes:

LL: local-local; LN: local-non-local; NL: non-local-local; NN: non-local-non-local.

* Significant at the $10 \%$ level; ** significant at the $5 \%$ level; *** significant at the $1 \%$ level. 
Consistent with the analysis in section 4.1 , government support has a positive influence on adoption of anti-flood measures. Government provision of information increases the probability that residents would adopt simple non-engineering measures, both types of non-engineering measure and all types of engineering measure. Government technical support has the greatest effect on adoption of engineering measures, while direct material support from government increases the proportion of residents adopting both types of non-engineering measures and both types of engineering measures.

The modelling results suggest that the influence of social capital on adoption of anti-flood measures is much more complex. Compared with NN residents, LL residents are more likely to adopt only simple non-engineering adaptation measures and both types of engineering adaptation measures, whereas NL residents are more likely to take only simple non-engineering adaptation measures. These results suggest that weak ties to social capital (Granovetter, 1973), based on the resident's social network related to career and social status, increase the probability that a resident will adopt anti-flood measures. However, strong ties to social capital, based on resident's blood relatives and location network, have less influence on adoption of anti-flood measures. Residents with 5 to 10 relatives (category 2) and more than 20 relatives (category 4) in the area are more likely to adopt only simple non-engineering measures, both types of non-engineering measures and both types of engineering measures than the residents with less than five relatives in the area (category 1). In contrast, compared to the residents with more than 100 phone numbers (category 4), 
residents with 20-100 phone numbers (categories 2 and 3) are less likely to take both types of non-engineering adaptation measures.

\section{Discussion and conclusions}

This study conducted a large-scale field surveys in the PRD area in China to analyse factors that influence residents' adoption of anti-flooding measure to mitigate the negative impact of urban flooding. Most residents (91.7\%) took some measures to protect their property against flooding. Most residents adopted simple measures, no matter they are engineering or non-engineering measures. The most popular simple engineering measure is moving valuable property to a safe place, and the most complex engineering measure is building a water-proof step. Some residents also chose to clear drains and strengthen their house. The most commonly adopted non-engineering measures are reducing travel, evacuating from dangerous areas and changing their work schedule or mode of work. Few residents adopted complex non-engineering measures, such as purchasing insurance, increasing savings and reducing spending. As most of the engineering and non-engineering measures residents adopted in this investigation are only to prevent or reduce the flood damage negatively, it is indicated that PRD residents lack awareness of coping with disaster actively in advance.

Unlike related research that argued that social capital was positively associated with the ability to cope with disaster (Chen et al., 2013; Lo et al., 2015), we found that its influence was more ambiguous. The social capital operationalized as the combination of Hukou (citizenship) and job location was positively associated with 
adoption of anti-flood measures, while the social capital operationalized as the number of blood relatives within three generations living in the same locality and number of phone contacts was negatively associated with adoption of non-engineering measures. Hukou (citizenship) is one of the most important indicators of a resident's stability and identity in one location in China. Local Hukou means that the resident has a local identity. According to Grannovetter's view (1973), individuals with weak social network ties are often denounced as generative of alienation and have a much stronger contribution to the integration of the community than individuals with strong social network ties formed by blood relationships. Therefore, we can consider local Hukou and a local job as weak social network ties, which could help resident build a deep sense of belonging to the area and form a strong local cohesion. This local cohesion will facilitate the individual to be more likely to invest in anti-flood measures and more likely to have access to relevant information. Someone without local citizenship is less likely to feel a sense of belonging and may consider him or herself a short-term resident and be reluctant to take non-engineering measures against flooding. Additionally, the weak ties suffer no restriction and easily become bridges to learn and exchange new knowledge and innovations. Information on the adaptation measures to urban flooding is easily diffused. Furthermore, weak ties play a role in affecting social cohesion, especially on community organization and collective activity. On the other side, blood relatives and close friend networks can be seen as strong ties to the social network, which may limit the information diffusion and leaning at a relatively small scale. 
This study also shows that governmental support has a positive influence on adoption of anti-flood measures. Information, technical support and direct material support provided by government increased the probability that residents would adopt non-engineering measures. Provision of early warning and mitigation information is the most popular and useful form of support, as it makes it easier for residents to take timely and effective mitigation measures, whether these are simple or complex. Technical and direct material support are less popular, while they still have a positive influence on adoption of engineering measures to mitigate the consequences of urban flooding. In particular, technical support has a positive influence on adoption of complex engineering measures. These results suggest that improving the efficiency and scope of government support would help to improve residents' capacity to cope with global climate change. However, we found during the field investigation that many residents were not satisfied with the government's actions for coping with disaster. Residents believed that many of government's actions did not have a close relation with their loss and that there were large gaps between the resident's needs and government's support. The core reason for this problem is that the community plays a weak role in urban anti-flooding.

The local community is the basic organization to organize residents to take adaptation measures. However, local communities are loose and inefficient at organization in the PRD area. As the most rapidly urbanized area, there are large changes in land-use and an agglomeration of immigrants in the PRD area, which cause this area to be a heterogeneous and dynamic sector with a wide diversity of 
land-use types that are highly susceptible to change. These spaces tend to grow at faster pace than those within urban areas, promoting transformation in social and cultural life and local value. A high proportion of immigrants, due to large-scale industry development, further causes heterogeneity and psychological disagreements within the community (Rosemary and Jennifer 2003), resulting in reduced social interactions and a weak network. Additionally, the limited time that community members have occupied their residence has resulted in poor organizational structures and a limited knowledge of the most appropriate adjustment measures that could be implemented for event mitigation (Hernandez-Guerrero et al., 2012). The community lacks not only money but also necessary resources, information, and facilities. Local people lack initiative and flexibility in case of emergency rescue because they may not know what measures are available and practical. Therefore, it is difficult to practice self-rescue and mutual help in these communities in the instance of a flood disaster (Yang et al., 2015).

Thus, it is essential to build appropriate emergency response practices at the community level. At the local community level, rescuers, materials, and technical support should be adequate and institutional mechanisms for local risk reduction, disaster preparation and self-reliance rather than engineering measures are necessary. Therefore, based on these results we provide several policy suggestions.

First, the government should take primary responsibility for undertaking community-level engineering measures to protect against the effects of flooding due to global climate change. The government's priority should be increasing the 
resources allocated to community-level engineering projects and enhancing cities' anti-disaster capability.

Second, local communities should play a critical role in disaster prevention and mitigation (Middelbeek et al., 2014). As the most rapidly urbanized place in China, an increasing number of surplus rural labour and residents will enter into cities and become urban residents. The structure of urban areas will become more complex, especially in South China, leading to fragmentation of social relationships and disintegration of social capital. Mutual exchange of information and assistance will become less common. A resident's disaster prevention and mitigation are normally taken by the household rather than by the community, which leads to the low efficiency of disaster prevention and more damage. Hence, the city government should enhance the role of urban community (Jiedao) in the organization and implementation of engineering and non-engineering measures against flooding. Additionally, it should promote the drafting of community-based adaptation strategies and the inclusion of the community in local adaptation plans.

Third, the community should put more effort into providing technical and information assistance to urban residents. Offering training courses, distributing leaflets and organizing disaster-prevention exercises would improve public awareness of disaster prevention and mitigation measures and ensure that residents have a better understanding of how to prevent flooding and mitigate its effects.

\section{Acknowledgements}


This research was funded by the Chinese National Basic Research Program of China (No.2012CB955702) and National Science Foundation (No. 41371142 and No. 41301112). The authors appreciate the field survey assistance provided by students at the Sun Yat-sen University and the Institute of Geographical Sciences and Natural Resource Research of Chinese Academy of Sciences. We would also like to thank two anonymous referees for their valuable comments and suggestions that have significantly improved this manuscript.

\section{References}

Adger, W. N. (2003). Social capital, collective action, and adaptation to climate change. Economic Geography, 79(4), 387-404.

Blennow K., \& Persson J. (2009). Climate change: motivation for taking measure to adapt. Global Environmental Change, 19, 100-104.

Blennow, K., Persson, J., Tomé, M., et al. (2012). Climate Change: Believing and Seeing Implies Adapting. PLoS One, 7(11), e50182. doi:10.1371/journal.pone.0050182

Bubeck, P., Botzen, W. J., \& Aerts, J. C. (2012). A review of risk perceptions and other factors that influence flood mitigation behaviour. Risk Analysis, 32(9), $1481-1495$

Carter, J.G., Cavan, G., Connelly, A., et al. (2015). Climate change and the city: Building capacity for urban adaptation. Progress in Planning, 95, 1-66.

Chamlee-Wright, E., Storr, V.H. (2009). Expectations of government's response to disaster. Public Choice, 144 (1-2), 253-274. 
Chan, F. K., Mitchell, G., Adekola, O., et al. (2012). Flood risk in Asia's urban mega-deltas drivers, impacts and response. Environment and Urbanization Asia, 3(1), 41-61.

Chen, H., Wang, J., \& Huang, J. (2014). Policy support, social capital, and farmers' adaptation to drought in China. Global Environmental Change, 24, 193-202.

Chen, X.H. (1999). Variation of flood in the Pearl River Delta and flood risk and insurance. Tropical Geography, 19(2),117-123.

China Daily. (2015). China's Pearl River Delta is world's largest urban area. [Online] Available from http://usa.chinadaily.com.cn/business/2015-01/27/content_19416179.htm

Coleman, J. (1990). Foundations of social theory. Boston, MA: Harvard University Press.

Du, S.Q., Rompaey, A.V., Shi, P.J., et al. (2015). A dual effect of urban expansion on flood risk in the Pearl River Delta (China) revealed by land-use scenarios and direct runoff simulation. Natural hazard, 77,111-128.

Eakin, H., Eriksen, S., Eikeland, P.-O., et al. (2011). Public sector reform and governance for adaptation: implications of new public management for adaptive capacity in Mexico and Norway. Environmental Manage. 47(3), $338-351$.

Eriksen, S., \& Selboe, E. (2012). The social organisation of adaptation to climate variability and global change: the case of a mountain farming community in Norway. Applied Geography, 33(0), 159-167. 
Frank, E., Eakin, H., \& Lopez-Carr, D. (2011). Social identity, perception and motivation in adaptation to climate risk in the coffee sector of Chiapas, Mexico. Global Environmental Change, 21(1), 66-76.

Fuchs, R., Conran, M., \& Louis, E. (2011). Climate change and Asia's coastal urban cities. Environment and Urbanization Asia, 2(1), 13-28.

Granovetter, M. (1973). The strength of weak ties. American Journal of Sociology, 78(6), 1360-1380.

Grothmann, T., \& Patt, A. (2005). Adaptive capacity and human cognition: The process of individual adaptation to climate change. Global Environmental Change, 15, 199-213.

Grothmann, T., \& Reusswig, F. (2006). People at risk of flooding: Why some residents take precautionary action while others do not. Natural Hazards, 38, 101-120.

Goulden, M. C., Adger, W. N., Allison, E. H., et al. (2013). Limits to resilience from livelihood diversification and social capital in lake social ecological systems. Annals of the Association of American Geographers, 103(4), 906-924.

Haddad, E. A., \& Teixeira, E. (2015). Economic impacts of natural disasters in megacities: The case of floods in Sao Paulo, Brazil. Habitat International, 45, 106-113.

He, C.F., Yang, L., \&Li, G.C.(2010). Urban Development and Climate Change in the Pearl River Delta. Lincoln Institute of Land Policy Working Paper. Beijing: Lincoln Institute of Land Policy. 
Hernandez-Guerrero, J., Vieyra-Medrano, A., \& Mendoza, M.E. (2012). Adaptation strategies in communities under precarious housing: flooding risks in the peri-urban sector of the city of Morelia, Michoacán, Mexico. Applied geography, 34, 669-679.

Huang, L., Duan, B., Bi, J., et al. (2010). Analysis of determining factors of the public's risk acceptance level in China. Human and Ecological Risk Assessment, 16(2), 365-379.

Hughes, S. (2015). A meta-analysis of urban climate change adaptation planning in the U.S. Urban Climate, 14, 17-29.

IPCC (Intergovernmental Panel on Climate Change). (2012). Summary for policy makers. In: Managing the Risks of Extreme Events and Disasters to Advance Climate Change Adaptation. A Special Report of Working Groups I and II of the Intergovernmental Panel on Climate Change. London: Cambridge University Press.

Kunreuther, H. (2006). Disaster mitigation and insurance: learning from Katrina. Annals of the American Academy of Political and Social Science, 604, 208-227.

Leonard, R. \& Onyx, J. (2003). Networking through loose and strong ties: an Australian qualitative study. International Journal of Voluntary and Nonprofit Organizations, 14(2), 189-203.

Lin N. (2008). A network theory of social capital. In: Castiglione dario, van Deth JW, Wolleb G, editors. The Handbook of Social Capital. London: Oxford 
University Press; pp. 50-69.

Liu, Y., He, S., Wu, F., et al. (2010). Urban villages under China's rapid urbanization: unregulated assets and transitional neighbourhoods. Habitat International, $34(2), 135-144$.

Lo, A.Y., Xu, B., Chan, F.K., et al. (2015). Social capital and community preparation for urban flooding in China. Applied Geography, 64, 1-11.

Middelbeek, L., Kolle, K., \& Verrest, H. (2014). Built to last? Local climate change adaptation and governance in the Caribbean-The case of an informal urban settlement in Trinidad and Tobago. Urban Climate, 8, 138-154.

Milman, A., \& Warner, B.P. (2016). The interfaces of public and private adaptation: Lessons from flooding in the Deerfield River Watershed. Global Environmental Change, 36, 46-55.

MOST (the Ministry of Science and Technology), CMA (China Meteorological Administration), and CAS (Chinese Academy of Sciences). (2011). The second national assessment report on climate change, Beijing: China Meteorological News Press.

Motoyoshi, T., Sato, T., Fukuzono, T., et al. (2004). Factors determining residents' preparedness for floods in modern megalopolises: the case of the Tokai flood disaster in Japan. Journal of Risk Research, 7, 775-787.

Pelling, M., \& High, C. (2005). Understanding adaptation: what can social capital offer assessments of adaptive capacity? Global Environmental Change, 15, 308-319. 
Pelling, M. (2011). Adaptation to climate change: From resilience to transformation. Oxon, U.K: Routledge.

Pretty, J., \& Ward, H. (2001). Social capital and the environment. World Development, 29(2), 209-227.

Putnam, R. D. (1995). Bowling alone: America's declining social capital. Journal of Democracy, 6(1), 65-78.

Rashid, H., Hider, W., \& McNeil, D. (2007). Urban riverbank residents' evaluation of flood evacuation policies in Winnipeg, Manitoba, Canada. Environmental Hazards, 4, 372-382.

Reguero, B. G., Losada, I. J., Díaz-Simal, P., et al. (2015) Effects of Climate Change on Exposure to Coastal Flooding in Latin America and the Caribbean. PLoS One, 10(7), e0133409. doi:10.1371/journal.pone.0133409.

Shaw R. (2012). Overview of community-based disaster risk reduction. Community Environ Disaster Risk Management, 10, 3-17.

Scolobig, A., Marchi, B., \& Borga, M. (2012). The missing link between flood risk awareness and preparedness: findings from case studies in an Alpine Region. Natural Hazard. 63, 499-520.

Suckall, N., Tompkins, E., \& Stringer, L. (2014). Identifying trade-offs between adaptation, mitigation and development in community responses to climate and socio-economic stresses: evidence from Zanzibar, Tanzania. Applied Geography, 46(0), 111-121.

Wang, G., Liu, Y., Wang, H., \& Wang, X. (2014). A comprehensive risk analysis of 
coastal zones in China. Estuarine, Coastal and Shelf Science, 140(0), 22-31.

Wang, Y. P., Wang, Y., \& Wu, J. (2009). Urbanization and informal development in China: urban villages in Shenzhen. International Journal of Urban and Regional Research, 33(4), 957-973.

Witvorapong, N., Muttarak, R., \& Pothosiri, W. (2015). Social participation and disaster risk reduction behaviors in Tsunami Prone Areas. PLoS One. doi:10.1371/journal.pone.0130862

Wolf, J., Adger, W. N., Lorenzoni, I., et al. (2010). Social capital, individual responses to heat waves and climate change adaptation: an empirical study of two UK cities. Global Environmental Change, 20(1), 44-52.

Yang, F. Chen, Z.J., Hu, J.H. (2013). Key technologies of early warning of urban water-logging in typical cities of Pearl River Delta Area. Proceeding of the 2013 annual conference of China water resources Association: S3 flood control and drought relief.

Yang, L., Scheffran, J., Qin, H., et al. (2015). Climate-related flood risks and urban responses in the Pearl River Delta, China. Regional Environmental Change, 15(2), 379-391.

Yu, H., Wang, B., Zhang, Y.-J., et al. (2013). Public perception of climate change in China: results from the questionnaire survey. Natural Hazards, 69(1), 459-472. 